\title{
РОЛЬ ТРЕХ СЛОВ ИЗ «НИКОМАХОВОЙ ЭТИКИ» В ФОРМИРОВАНИИ ЗЕМЕЛЬНО-ИМУЩЕСТВЕННЫХ ОТНОШЕНИЙ В РОССИИ
}

\author{
Михаил Абрамович Креймер \\ ФБУН «Новосибирский НИИ гигиены» Роспотребнадзора, 630108, Россия, г. Новосибирск, \\ ул. Пархоменко 7, кандидат экономических наук, ведущий научный сотрудник научной части, \\ тел. (383)343-34-01, e-mail: m.kreimer@ya.ru
}

Выполнен историко-методологический обзор, характеризующий прикладные аспекты применения политэкономических категорий в хозяйственной практике страны. Показано, что фундаментальное содержание земельно-имущественных отношений должно строится на принципах этики, раскрывающихся экономическим поведением, как ценность, а при её излишках, как стоимость. Категория хрематистики расширяет содержание принципов и приводит к образованию законодательства и политики в выборе системы оценок.

Ключевые слова: земельно-имущественные отношения, система национальных счетов, стоимость, ценность, хрематистика, федеральный стандарт оценки

\section{THE ROLE OF THREE WORDS FROM "NIKOMAKHOVA ETHICS" IN THE FORMATION OF LAND-PROPERTY RELATIONS IN RUSSIA}

\begin{abstract}
Mikhail A. Kramer
"Novosibirsk Institute of Hygiene" Rospotrebnadzor, 7, Plakhotnogo St., Novosibirsk, 630108, Russia, Ph. D., Leading Researcher of the Scientific Part, phone: (383)343-34-01, e-mail: m.kreimer@ya.ru

A historical and methodological review describing the applied aspects of the use of political economic categories in the economic practice of the country is performed. It is shown that the fundamental content of land and property relations should be based on the principles of ethics, which are revealed by economic behavior as value, and with its surplus, as value. The category of chrematistics expands the content of the principles and leads to the formation of legislation and policy in the choice of the assessment system.
\end{abstract}

Keywords: land and property relations, system of national accounts, cost, value, chrematistics, Federal valuation standard

Земельно-имущественные отношения XXI века в РФ сложились на основании методологии Федеральных стандартов оценки, включающих такие агрегаты, как средства труда (ФСО 13 и 10); институты рынка (4 и 7); бизнеса (8 и 12); банковского сектора (11 и 9). Практика применения ФСО в землепользовании и управлении экономикой является недостаточной, если они строятся только на геопространственном обеспечении оценки недвижимости, с учетом геодезических решений и экологии. Мерой является экономическая категория стоимости, исходящая из ценности и порождающая хрематистику. Эти базовые экономические понятия содержат этические рассуждения, которые приведены Аристотелем в обращении-напутствии сыну и его окружению. За 2320 лет они обросли множеством теорий и критикой, однако, в экономике нет других метафизических основ. 
Такое критическое понимание обусловлено тем, что категория стоимости пропорциональна трудовой деятельности; ценность - формирует имущественное содержание оценки, а хрематистика - обещанную финансовую выгоду ценным бумагам. Экономические теории занимаются поиском и доказательством прямо пропорциональных закономерностей между капитальным вложением и прибылью; ценность - формирует масштабы рынка от бартера до Всемирной торговой организации; хрематистика - акционерные деньги и институты по управлению виртуальной экономикой. Если современная экономика выходит за границы стоимости, то есть ли основания применять ФСО в виртуальном пространстве с цифровой валютой? [1]

Приведенные категории образуют метрическую систему экономики, как начало (вектор и шкала) для других прикладных отраслей хозяйствования. Базовым вектором является категория ценности благ для жизни человека. Их шкала соответствует понятиям здоровья и воспроизводства человека. Второй вектор возможен при наличии излишков производства, «утилизация» которых по стоимости осуществляется, исходя из принятых этических норм в обществе. Третий вектор, наоборот, достраивается, если в обществе есть дефицит и коммерческий интерес в расширении материального производства. Однако, для него необходимы заёмные средства.

Поэтому экономика, «как этология», блуждает, как наука, между векторами, ограничиваясь правом на основе этики (нравственности и морали). Только этические нормы могут объяснить величину прожиточного минимума, безусловного базового дохода, прибыли и различных налогов, включая измеренные ФСО. Перечень экономического поведения человека в обществе формируется совместным проживанием на территории жилища, поселения, страны и межгосударственным обременением.

\section{Этика стоимости}

В общих замечаниях к этическим сочинениям приводится, что «Никомахова этика» - это психология Аристотеля, исследующая «нравственные задачи гражданина и государства ...» [2, с. 6], возникающие вокруг стоимости: в виде мущества измеряемого деньгами [2, с. 121]. Стоимость формирует поведение в дружбе [2, с. 242 и 244]; определяет «кому же из двух установить стоимость», чтобы отдать или получить вознаграждение; определяет правосудность [2, с. 246]. Однако, Аристотелева модель стоимости в интересах человека не тождественна более поздней коллективной трудовой деятельности. В экономике она тождественна таким терминам как полезность, ценность и другим, позволяющим измерять каждому свои «трудовые часы, дни, года» для получения своей доли благ (заработная плата, премия, пенсия). Если стоимость является «линейкой» со шкалой измерения трудозатрат для оценки сопоставимости товаров, то может ли она применяться там, где труд опосредован недвижимостью, или накоплением банковских обязательств, или налогами и неналоговыми сборами. Если стоимость, как метрическая система, ближе к полезности вещи, отражающая физиологические особенности 
потребления, то для коммерции (найти товар подешевле) и спекуляции (продать товар подороже) должны действовать другие принципы построения стоимости. Имеет ли право будущее поколение измерять стоимость, исходя из своей предпочтительности к натуральному обмену вещами, которые были сделаны с учетом достижений труда прошлых поколений?

Апробация категории стоимости в виде денег и налогов привела к развитию классической теории политической экономии, построению выводов о том, что «К счастью, в законах стоимости нет ничего, что осталось бы [1848 г.] выяснить современному или любому будущему автору; теория этого предмета является завершенной» [3, с. 172]. Краткое изложение в 17 пунктах этого суждения актуализировало развитие неоклассического направления, разработку теории предельной производительности; теории общего равновесия, согласно которой механизм свободной конкуренции и рыночного ценообразования обеспечивает справедливое распределение доходов и полное использование экономических ресурсов; экономическую теорию благосостояния, принципы которой положены в основу современной теории государственных финансов; теорию рациональных ожиданий и др.

Другие пункты по Дж. Миллю получили применение в развитии марксистской политической экономии. Главный научный труд для социалистических преобразований «Капитал. Критика политической экономии» [4] в третьем томе (1894 г.) содержит завершающий Отдел (номер 7) «Доходы и их источники». «Обрывающаяся рукопись» [4, с. 458], состоит из 79 страниц, 5 глав. После критики политической экономии К. Маркс завершает учение о капитале практически новым содержанием «Доходы и их источники» со следующими темами: триединая формула; к анализу процесса производства; видимость, создаваемая конкуренцией; отношения распределения и производственные отношения; классы.

Принятая Организацией экономического сотрудничества и развития ООН, а также Европейской комиссией, Международным валютным фондом и Всемирным банком Система национальных счетов (далее СНC) в редакции 2008 г., отражает методологию политической экономии, начиная с В. Петти и Ф. Кенэ. Стоимость, как экономическая категория в тексте СНС, образует следующие политэкономические обороты: стоимость + амортизированная, балансовая, валовая добавленная, восстановительная, добавленная, залоговая, инвестиционная, интеллектуальной собственности, информационная, историческая (первоначальная), кадастровая, ликвидационная, меновая, нарицательная, настоящая, недвижимости, нематериальных активов, номинальная, обменная, остаточная, потребительная, прибавочная, рыночная, справедливая, таможенная, текущая, трудовая, улучшений земли, услуг, чистая добавленная, экономическая валовая. Приведенные в СНС синонимы важны для построения баланса между «прибавочной (добавочной) стоимостью» и финансированием общественного развития, включающие средства труда, измеряемые как ФСО 13 и 10; институты рынка (ФСО 4 и 7), бизнеса (ФСО 8 и 12); банковского сектора (ФСО 11 и 9). 


\section{Утерянная ценность}

Дискуссия о применении рассматриваемых словоформ и их перевода с языка авторов для других народов, больше всего возникла в марксизме. П. Н. Кондрашов [5] приводит четыре этапа перевода «Капитала» К. Маркса в России. Первый перевод был завершен в 1872 г. Н. Ф. Даниельсоном (1844 - 1918); второй - сделан П. Б. Струве $(1870$ - 1944) в 1899 году и третий в 1907 - 1909 годах - И. И. Скворцовым - Степановым $(1870-1958)$ совместно с А. Богдановым и В. Базаровым. История перевода интересна, т. к. она позволяет увидеть (разумом) кристаллизацию теории, выделение приоритетов и конечное содержание базовых знаний. Выбор между стоимостью и ценностью привел к разделению российских социал-демократов на большевиков и меньшевиков - бесполезное и бессмысленное для научной теории. Один термин не сможет объяснить все частные случаи в политэкономии.

Два основания политической экономии в России как ценность сформировались в работах Р. М. Орженцкого $(1863$ - 1923) и П. Б. Струве, а как стоимость И. И. Скворцова-Степанова. В очерках раскрывается следующее содержание полезности и цены: I) потребность преимущественно раскрывается индивидуальным питанием; II) степень полезности - «субъективное значение потребности, удовлетворение которой мы испытываем ...» [6, с. 14]; III) обмен между людьми возможен излишками собирательства; IV) обмен в условиях конкуренции осуществляется по «определенной действительной цене, ... [которая] становится (почти) обратно пропорциональной представленным степеням полезности» [6, с. 58]; V) обмен в условиях разделения занятий возможен, « т.к. изменяется только цена данных предметов, меновые же отношения всех других предметов остаются прежними» [6, с. 69]; VI) абстрактная полезность и её представитель деньги, «включают в себя известную меру такой полезности, ... становится мерой полезности всякого другого предмета ...» [6, с. 76]; VII) цена предметов высших порядков «составляется издержками производства, к которым относится прибыль на капитал» $[6$, с. 89], что является положением теории о том, что «цена продуктов пропорциональна количеству вложенного в них труда» [6, с. 90].

Р. М. Орженцкий считал, что никому не удалось показать с достаточной убедительностью, что «именно заключающееся в них [физическое или психическое] делает их экономическими явлениями» $[7$, с. 2]. В то же время «Определение экономического явления посредством юридического признака» он считал симптоматическим [7, с. 12]. В избирательном применении юридических норм Р. М. Орженцкий видел указание на природу экономических явлений [7, с. 12].

Политэкономия П. Б. Струве раскрывается в двух научных статьях о политической экономии (1923 г.) «Хозяйствование, хозяйство, общество» и «Некоторые основные понятия экономической науки», опубликованные в Избранных сочинениях (1999 г.). Посередине творческого пути П. Б. Струве пишет (заключает, обобщает): «Для научного рассуждения необходима точная выработка понятий и соответственная отточенная терминология. Исходными пунктами нашего рассуждения являются два понятия: хозяйствование и хозяйство» $[8$, с. 213]. Анализ 
посвящен значимости и различию между первичным и вторичным хозяйствованием, которые являются функциональным целым ценности [8, с. 219].

Первичное хозяйствование (конструирование определения по тексту П. Б. Струве) - не самоцельная и не самоценная функция, или натуральное хозяйство. Оно субъективное, бесконечное «многообразие несводимых ни к какому единству потребностей непосредственно противостоит объективному, столь же мало сводимому к какому-нибудь единству, многообразию полезностей и усилий. Ибо потребности, или, точнее, ощущения потребностей первоначально не только многообразны, но и несоизмеримы» [8, с. 215]. Из этой размерности он определяет, «что первичное хозяйствование как раз и характеризуется отсутствием хозяйственного измерения», т. е. является «искусственным, будет всегда «артефактом» в точном социологическом смысле слова» [8, с. 216]. Социологический смысл раскрывается следующим содержанием: «отсутствие естественного измерения хозяйственных вещей и действий; оно не есть историческая категория, не есть какой-то разрез действительности, поэтому измерения в первичном хозяйствовании могут быть производимы лишь человеческой волей» [8, с. 217]. Поэтому «В первичном хозяйствовании нет того столкновения или соприкосновения разных воль, которое творит для хозяйствующих субъектов наперед данное им измерение хозяйственных благ и действие, как их собственных, так и чужих. В первичном хозяйствовании каждый хозяин должен сам «творить», «делать», «выдумывать» такое измерение» [8, с. 228]. Социологический смысл формируется физиологическим составом приобретения и использования на основе усилий труда, поэтому первичное хозяйствование дано «в двух измерениях: потребности и количества» [8, с. 232].

Вторичное хозяйствование (конструирование определения по тексту П. Б. Струве) - идеально-типическое понятие денежно-ценового хозяйствования $[8$, c. 216]; характеризуется «естественным» измерением и таковой же измеримостью хозяйственных вещей и действий [8, с. 217]: «ценовым, ценностным, или денежно-ценовым» [8, с. 219] для взаимохозяйствования (взаимодействующих) хозяйств [8, с. 233]. Поэтому оно «дано нам в трех измерениях: потребности, количества и цены (ценности) [8, с. 232). Без собственности, самоопределения и возмездности, нет вторичного хозяйствования [8, с. 230] и сопряженности между ценой, деньгами и рынком. Цены и деньги - естественные явления, вытекающие из легальных основ: «собственности, хозяйственного самоопределения (автономии) и возмездности хозяйственных действий» [8, с. 249].

В доступных работах П. Б Струве не встретилось слово «стоимость», как экономическая категория. Во вступительной статье К. А. Соловьева (канд. историч. наук) к избранным трудам П. Б. Струве приведено, что он «доказывал неубедительность марксистской теории стоимости» [8, с. 10]. Поэтому нам доступны следующие выводы о ценности. К характеристике развернутого хозяйствования П. Б. Струве потребности, количество благ и ценностные величины, из которых последние «суть настоящие величины - и это отличает их от потребностей или ощущений потребностей — и к тому же они являются хозяйственно измеримыми величинами - и это отличает их от количеств благ, как простых количеств» [8, с. 218]. Для обоснования экономических явлений важно руководствоваться 
следующим заключением: «В натуральном хозяйствовании нет хозяйственного измерения, т.е. нет ни цен, ни ценности (ценность, как с удивительной отчетливостью выражает русский язык, есть производное цене), ни денег, которые в своей основе опять-таки указуют не на что иное, как на измерение и измеримость «хозяйственного». [8, с. 219]. Далее, только деньги «создают подлинное ценностное измерение благ. Тот «механизм», который непрерывно производит это внутриположное и, в то же время, объективное измерение, есть рынок» [8, с. 247]. Денежные цены становятся ценностным измерением, т. е. «особым специфическим методом контроля и учета хозяйствования, и последнее выделяется в качестве особой системы жизни и культуры» [8, с. 249].

В избранных произведениях И. И. Скворцова-Степанова, опубликованных в 1930 -1931 гг., приведены следующие политэкономические выводы «... учение о стоимости - основа всей экономической теории марксизма и основа исторического материализма» [9, с 269]. Далее, он считал, что стоимость не составляет всего марксизма, так как является исторической категорией, не исчерпывающей содержания всей теории, которую можно рассматривать как абстрактно-логическую функцию. И. И. Скворцов-Степанов О программах марксистского образования, ноябрь 1922 г, писал «... учение о стоимости - только ключ, который может быть и очень грубым, и очень тонким ... для познания действительности, а не просто для умственной гимнастики» [9, с. 271]. Поэтому он критиковал дискуссии широких слоёв населения «... на тему о производительном и непроизводительном труде, о стоимости и меновой стоимости» [9, с. 275], которая действительно касается не только категории стоимости, но и ценности и хрематистики.

В статье, опубликованной во втором томе избранных произведений [9] «Необходимость урегулировать отношения между деревней и городом. (1 февраля) 19 января 1918 г.» И. И. Скворцов-Степанов приводит структуру цены, по которой продаются товары: 1) сумма, затраченная на содержание работника, производившего эти товары; 2) «... стоимость, соответствующая сношенной части орудий и машин и потраченным на производство сырым и вспомогательным материалам» [9, с. 180]. Таким образом покупатель приобретает ценность, но оплачивает издержки (затраты) производства. «Если все это не возвратится к производителю в цене проданного им товара, - или не возвратится к железным дорогам в цене пассажирских билетов и в плате за перевезенные товары, - то производство без помощи со стороны начнет разрушаться и падать. Не будет достаточных средств на покупку хлопка и топлива, рельс, вагонов и паровозов, семян, удобрений, лошади, плуга и т. д. Долго так тянуться не может. Быстро станет надвигаться экономическая смерть» (с. 180). Возврат осуществляется не в виде материальных средств труда и производства, а виде финансовых записей о движении денег. Таким образом стоимости, которая формируется на стадии производства и продажи, далее сопутствует информационная стоимость о возможностях следующего экономического цикла.

По определению А. М. Бирмана, главная проблема начала ХХ века (1917 год), вызвавшая большой интерес во всем мире: «каковы внутренние побудительные причины непрерывного развития производительных сил при социализме, когда 
невозможна конкуренция? Это серьезный вопрос, и он смущал многих мыслителей, в общем доброжелательно относившихся к идеям социализма, но не видевших реальных путей его построения.

Ленин ответил на этот вопрос знаменитой статьей «Как организовать соревнование?». «На смену разорительной конкуренции, писал Ленин, придет творческое соревнование талантов, которых в народе миллионы, и сила соревнования будет пружиной, которая двинет общественное развитие и обеспечит победу нового общественного строя над старым». Вот на чем держался социализм, нужны были институты власти. Однако, социалистическое (коммунистическое) соревнование не построило безкризисное общество. Здесь можно увидеть искажение сути классической и марксистской теории политической экономии. Это не догматизм, а отступление еще ниже в область российской религиозной утопии (благое место, которого нет на земле). Экономическим основанием такого регресса были природные богатства и бедность основных масс населения. Страна вела по сути феодальный способ хозяйствования. Нарождающийся капитализм в 1917 году не был принят народными массами. Капиталистический способ производства - это интенсификация труда посредством постоянного обновления средств производства за счет доли прибыли. В России того времени такой механизм был не приемлем, потому что были в избытке природные богатства и было мало частной собственности.

\section{Хрематистика цивилизации}

Достижима ли высшая форма общества не разрушающая начальную этическую стоимость. Введение хрематистики важно для понимания перехода от классической теории стоимости к «вульгарной политической экономии» на основе субъективности. И. Г. Блюмин $(1897-1959)$ писал, что К. Маркс дал классическое определение политической вульгарной: «... в отличие от классической политической экономии, которая изучала внутренние зависимости буржуазного общества, вульгарная политическая экономия вращается в кругу внешних кажущихся зависимостей, т. е. рассматривает явления такими, какими они выступают на поверхности» $[10$, с. 105].

Для биогеохимической деятельности государства необходимо создание средств труда обеспечивающих не только количественный рост экологических закономерностей, но и увеличивающих вовлечение химических элементов и на их основе соединений в метаболизм человека. Аристотель видел такое расширение экономики с применением хрематистики. Для индустриализации нужны другие источники доходов, превышающие результаты трудовой деятельности. Для распоряжения богатствами тем, что измеряется более чем благами для жизни, необходима биогеохимическая функция, а в экономике - хрематистика, как искусство распоряжаться богатствами, т. е. «делать деньги» для средств труда.

В главном труде Карла Маркса по политической экономии «Капитал. Критика политической экономии», состоящем из 7-ми томов, 2-го собрания сочинений, только в первом томе «Книга I Процесс производства капитала» используется понятие хрематистики для понимания движения капитала [11, с. 163 и 175]. 
В первом (23) и последующих томах (24, 25-1 и 25-2, 2-го полного издания) К. Маркс для учения о прибавочной стоимости не стал применять хрематистику, а социализм построил на материалистическом понимании истории и диктатуре пролетариата.

\section{Заключение}

Понимание земельно-имущественных отношений может быть раскрыто на основании метрической система экономики. Для выделения ценности необходимы средства труда, создающие экономические явления, доступные как трудовая теория стоимости и измеряемые ФСО 13 и 10. Институты рынка создаются на основании теории предельной полезности (плавающей ценности), которая может применяться в ФСО 4 и 7. Бизнес отрывается за счет хрематистики, но страдает издержками, поэтому применяют ФСО 8 и 12. Для управления тремя экономическими категориями доступна информационная теория стоимости и ФСО 11 и 9.

\section{БИБЛИОГРАФИЧЕСКИЙ СПИСОК}

1. Креймер М. А. Правдоподобные рассуждения в экономических исследованиях // Интерэкспо ГЕО-Сибирь. XV Междунар. науч. конгр., 24-26 апреля 2019 г., Новосибирск [Текст] : сб. материалов в 9 т. Т. 3 : Междунар. науч. конф. «Экономическое развитие Сибири и Дальнего Востока. Экономика природопользования, землеустройство, лесоустройство, управление недвижимостью». - Новосибирск: СГУГиТ, 2019. № 1. - 285 с. - (141 - 149).

2. Аристотель Сочинения в 4-х т., Т 4. Пер. с древнегреч. Общ. Ред. А.И. Доватура. - М.: Мысль, 1983. -830 с.

3. Милль Дж. С. Основы политической экономии. Кн. 3 Обмен. Том 2. - М.: Прогресс, 1980. $-482 \mathrm{c}$.

4. Маркс К. Капитал. Критика политической экономии. Том 3, Книга 3: Процесс капиталистического производства, взятый в целом. / Соч. Изд. 2-е - М. Госполитиздат, 1962. - 558 с.

5. Кондрашов П. Н. Нелепость, ставшая привычкой // Свободная мысль. - 2016. - № 5 C. $203-217$.

6. Орженцкий Р. М. Учение о ценности у классиков и канонистов. Политико-экономический очерк. Одесса: Типография штаба округа. $-1896 .-264$ с.

7. Орженцкий Р. М. Учение об экономическом явлении. Введение в теорию ценности. Одесса: Экономическая типография. - 1903. - 386 с.

8. Струве П. Б. Избранные труды. - М.: РОССПЭН, 2010. — 560 с.

9. Скворцов-Степанов И. И. Избранные произведения. Т. 2 Под ред. П. А. Красикова, Н. Л. Мещерякова, М. А Савельева, В. Г. Сорина, П. Г. Сенниковского. Гос. соц.-экономическое издательство, 1931. $-578 \mathrm{c}$.

10. Блюмин И. Г. История экономических учений (Очерки теории). Под редакцией профессора Ф. Я. Полянского - М.: Высшая школа, 1961. - 268 с.

11. Маркс К. Капитал Критика политической экономии. - Т. 1. - Кн. 1: Процесс производства капитала / Маркс К., Энгельс Ф. Соч. - 2-е изд. - Т. 23. - М., 1960. - 920 с.

(C) М. А. Креймер, 2021 